\title{
PROFIL PRAMUWISATA KAWASAN GEOPARK CILETUH PALABUHANRATU: KOMPETENSI DAN TANTANGANNYA DALAM MENGHADAPI ERA TOURISM 4.0
}

\author{
Ahmad Yani ${ }^{1 *}$, Asep Mulyadi ${ }^{2}$, Rosita $^{3}$ \\ 1,2,3Program Studi Pendidikan Geografi, FPIPS, Universitas Pendidikan Indonesia \\ *ahmadyani@upi.edu
}

\begin{tabular}{l}
\hline \multicolumn{2}{c}{ INFO ARTIKEL } \\
\hline Riwayat Artikel : \\
Dikirim $\quad: 30-04-2020$ \\
Disetujui $\quad: 29-05-2020$ \\
Diterbitkan $: 23-06-2020$ \\
\hline
\end{tabular}

\section{Kata Kunci :}

Ciletuh, Geopark,

Kompetensi, Pramuwisata,

Tourism 4.0

ABSTRAK

Abstract: The role of guides in a tourist area is significant because they are "ambassadors" for the state, management, and the local community. However, their existence is still not being noticed. In facing the Tourism 4.0 era, their challenges are getting more challenging because technology will displace them. They are threatened to become victims of disruption from these technological advances. The results showed that tour guides' qualifications and competence in the Ciletuh Palabuhanratu Geopark are still relatively low. This is due to the lack of attention from all parties. This research recommends that local governments, business actors related to tourism services (hotels, restaurants, banks, etc.) set aside their CSR to conduct training for guides through official organizations (HPI) in turns and are mutually beneficial.

\begin{abstract}
Abstrak: Peran pramuwisata di suatu kawasan wisata sangat penting karena mereka adalah "duta" bagi negara, badan pengelola, dan masyarakat setempat. Namun demikian, keberadaan mereka masih kurang diperhatikan. Dalam menghadapi era Tourim 4.0 tantangan mereka semakin berat karena akan tergeser oleh kehadiran teknologi. Mereka terancam menjadi korban disrupsi dari kemajuan teknologi tersebut. Hasil penelitian menunjukkan bahwa kualifikasi dan kompetensi pramuwisata di Kawasan Geoapark Ciletuh Palabuhanratu relatif masih rendah, hal ini karena kurangnya perhatian dari semua pihak. Penelitian ini merekomendasikan kepada pemerintah daerah, pelaku usaha yang terkait dengan jasa pariwisata (hotel, resporan, bank, dll) agar menyisihkan CSR-nya untuk melakukan pelatihan kepada pramuwisata melalui organisasi resmi (HPI) secara bergiliran dan saling menguntungkan.
\end{abstract}

\section{PENDAHULUAN}

Geopark Ciletuh Palabuhanratu sudah memperoleh predikat Unesco Global Geopark (UGGp) sejak pada 17 April 2017 dan berlaku hingga 17 April 2022. Masih ada sejumlah rekomendasi atau catatan yang harus dipenuhi jika ingin tetap dipertahankan sebagai UGGp. Lokasi Geopark Ciletuh Palabuhanratu berada di Kabupaten Sukabumi provinsi Jawa Barat. Luas wilayah Geopark Palabuhanratu sekitar 128 ribu hektar yang meliputi 8 kecamatan dan
74 desa/keluarahan di bagian Selatan Kabupataen Sukabumi.

Salah satu rekomendasi Tim Asesor UNESCO pada saat penilaian adalah agar tersedia modul-modul pelatihan untuk guide lokal, pemilik homestay, anggota asosiasi masyarakat yang menaungi kepariwisataan. Tujuannya agar stakeholder geoprak lebih profesional, meningkat wawasannya dan meningkat keterampilannya dalam mengintegrasian materi geodiversity, biodiversity, dan cultural diversity yang ada di 
\begin{tabular}{lcr}
\hline kawasan geopark & (Asy'arie, & 2019). \\
Rekomendasi & inilah & yang \\
kemudian
\end{tabular} memotivasi penulis untuk meneliti lebih dekat tentang keberadaan komunitas pramuwisata (tour guide).

Kajian yang menunjukkan pentingnya peranan pramuwisata dalam kegiatan pariwisata telah banyak dikaji. Black dan Weiler (2005) menyebutkan sepuluh perananan pramuwisata antara lain penyedia informasi, fasilitator sosial, pembawa acara budaya, motivator nilai-nilai konservasi, penafsir lingkungan alam dan budaya, penggerak orang. Dia juga menyebutkan tanggung jawab lainnya dari para pemandu wisata yaitu sebagai guru atau instruktur, petugas keamanan, "duta" bagi negaranya, perwakilan dari masyarakat setempat, penghibur, mengatasi masalah, orang kepercayaan dan bahkan sebagai konselor.

Selanjutnya Cohen (1985), Ap dan Wong (2001), Dahles (2002), Cohen, Maurice \& Cohen (2002) dan Yu, Weiler dan Ham (2001), Çetinkaya and Öter (2016) memiliki pemikiran yang relatif sama yaitu bahwa pemandu wisata memiliki peranan multi-talenta yaitu (1) Seorang pemimpin yang mampu memikul tanggung jawab pada keselamatan dan kenyaman wisatawan; (2) Pemberi informasi dan sumber pengetahuan; (3) Seorang mentor yang tugasnya menyerupai peran guru, tutor, instruktur atau penasihat); (4) Seorang mediator dan perantara budaya yaitu berperan langsung dalam menengahi pertukaran budaya antara pengunjung dan budaya tuan rumah; (5) Seorang pendidik untuk membantu wisatawan memahami tempat mereka mengunjungi; (6) Seorang analisis atau pemerhati banyak hal untuk membantu wisatawan untuk memahami banyak topik seperti politik, ekonomi, masyarakat, budaya, agama, pengetahuan umum, pendidikan, kesehatan, dan lain-lain; (7) Duta besar yang menyampaikan keramahan dan hadiah tujuan dengan cara yang membuat pengunjung ingin kembali; dan (8) Tuan rumah yang menciptakan lingkungan yang nyaman bagi wisatawan yang menunjukkan kualitas layanan sehingga wisatawan lebih lama tinggal dan menghasilkan manfaat ekonomi bagi masyarakat lokal.

Selanjutnya perlu juga diestimasi peran pemandu wisata pada era industri pariwisata 4.0 yaitu suatu kegiatan pariwisata yang memanfaatkan perkembangan teknologi di era industri 4.0. Korže (2019) menyebutkan beberapa teknologi yang paling penting dalam era tourism 4.0 yaitu adanya unsur IoT (Internet of Things), Big Data, Augmented Reality (AR), Virtual Reality (VR), Technology-based Business Models, Mobile Technology, Artificial Intelligent (AI) dan Robots.

Kehadiran teknologi di atas selain menjadi peluang tetapi juga menjadi tantangan yang cukup berat. Misalnya adanya teknologi IoT (Internet of Things), agent travel akan mudah mendapat pelanggan karena wisatawan dapat memesannya lewat aplikasi, namun tantangannya bermunculan wisatawanwisatawan yang melakukan perjalanan wisata secara mandiri yang biasa disebut dengan "Self-organised holidays \& independent travelers" (Nurdin, 2019). Virtual Reality (VR) yaitu teknologi yang membuat pengguna dapat berinteraksi dengan lingkungan yang ada dalam dunia maya sehingga pengguna merasa berada di dalam lingkungan tersebut. Informasi tentang objek wisata sudah cukup lengkap sehingga tidak mebutuhkan tour guide. Tantangan paling berat adalah Technology-based Business suatu yaitu teknologi starup yang memotong jalur antara sellers dan buyers untuk berbagai keperluan wisatawan mulai dari pemesanan tiket pesawat, booking hotel, transportasi lokal bahkan saat ini sudah terbiasa untuk memperoleh fasilitas homestay yang berada di pinggiran dapat dijangkau oleh wisatawan melalui aplikasi Airbnb, Oyo, Airi, Reddoorz dan lain-lain.

Dengan gambaran tantangan yang sangat berat, dibutuhkan usaha yang lebih keras yaitu melalui peningkatan kompetensi untuk dapat memanfaatkan teknologi era industri 4.0. Jika tidak mampu meningkatkan kompetensi diri maka pelaku bisnis travel agen dan para pramuwisata adalah pihak yang akan terkena dampak disrupsi.

Untuk memulai usaha ke arah peningkatan kompetensi paramuwisata di kawasan Geopark Ciletuh Palabuhanratu, adalah melalui pemetaan profil pramuwisata melalui penelitian yaitu dengan dua pertanyaan yaitu (1) bagaimana kualifikasi dan kompetensi pramuwisata di kawasan Geopark Ciletuh Palabuhanratu dan (2) peluang apakah yang dapat diambil untuk mempertahankan eksistensinya?. Penelitian ini penting dilakukan 
sebagai baseline dalam pembinaan di masa yang akan datang.

\section{METODE PENELITIAN}

Penelitian ini menggunakan metode dekriptif yang ingin menggambarkan profil umum para pemandu wisata di Kawasan Geopark Ciletuh Palabuhanratu. Partisipan yang bersedia memberi informasi adalah anggota HPI DPC Kabupaten Sukabumi yang digali informasinya melalui pengisian angkat dan test secara online. Jumlah partisipan $42(60 \%)$ dari 70 anggota HPI DPC Kabupaten Sukabumi. Selain itu, dilakukan wawancara kepada beberapa stakeholder yang relevan.

\section{HASIL DAN PEMBAHASAN}

Profil Umum Partisipan Penelitian

Profil pertama yang dapat direkam adalah proporsi dari jenis kelamin yaitu $30(71 \%)$ laki-laki dan 12 (29\%) perempuan.

Tabel 1. Usia Pramuwisata

\begin{tabular}{crr}
\hline Usia & F & $\%$ \\
\hline $1(<25)$ & 3 & 7,14 \\
$2(25-29)$ & 17 & 40,48 \\
$3(30-34)$ & 12 & 28,57 \\
$4(35-39)$ & 7 & 16,67 \\
$5(40-44)$ & 3 & 7,14 \\
\hline & 42 & 100,00 \\
\hline
\end{tabular}

Pengalaman sebagai pemandu relatif baru. Mereka yang memiliki pengalaman di bawah 4 tahun ada 26 orang (61\%); pengalaman $5-9$ tahun ada 12 orang (29\%), dan yang lebih dari 10 tahun ada 4 orang $(9,6 \%)$. Alasan menjadi pramuwisata sebagian hanya sebagai pekerja sampingan seperti data di tabel berikut.

\section{Tabel 2 Status Pekerjaan Pramuwisata}

\begin{tabular}{lrr}
\hline Status Pekerjaan & F & \\
\hline Pekerjaan pokok & 11 & 26,19 \\
Pekerjaan sampingan & 23 & 54,76 \\
Mengisi waktu luang & 2 & 4,76 \\
Lainnya & 6 & 14,29 \\
\hline & 42 & 100,00 \\
\hline
\end{tabular}

Penghasilan atau pendapatan partisipan dari profesinya sebagai pramuwisata gambarannya sebagai berikut.

Tabel 3. Pendapatan dari kegiatan Pramuwisata

\begin{tabular}{|l|r|r|}
\hline Pendapatan (Rp.) & $\mathrm{F}$ & \multicolumn{1}{|c|}{} \\
\hline$<1$ juta per bulan & 16 & 38,10 \\
\hline $1-2$ juta per bulan & 20 & 47,62 \\
\hline $2-3$ juta per bulan & 5 & 11,90 \\
\hline$>3$ juta per bulan & 1 & 2,38 \\
\hline & 42 & 100,00 \\
\hline
\end{tabular}

Selanjutnya tergali pula kondisi pekerjaan pokoknya. Ternyata, kebanyak sudah memiliki pekerjaan, hanya sekitar $28,57 \%$ yang belum memiliki pekerjaan tetap.

Tabel 4. Pekerjaan pokok Pramuwisata

\begin{tabular}{lrl}
\hline \multicolumn{1}{c}{ Pekerjaan Pokok } & F & \multicolumn{1}{c}{$\%$} \\
\hline Pegawai Negeri & 2 & 4,76 \\
Karyawan swasta & 17 & 40,48 \\
Pedagang/jasa angkutan & 11 & 26,19 \\
Tidak ada pekerjaan lain & 12 & 28,57 \\
\hline & 42 & 100,00 \\
\hline
\end{tabular}

Dari rangkaian data di atas dapat disimpulkan bahwa usia pramuwisata di kawasan Geopark Ciletuh Palabuhanratu adalah dari usia produktif dan nampaknya profesi pramuwisata belum dapat diandalkan sebagai usaha yang menjanjikan sehingga tidak dijadikan mata pencaharian pokok. Jika dilihat dari pengalamannya, umumnya "pendatang baru" di bidang pramuwisata yang bisa jadi pilihan menjadi pramuwisata hanya bersifat sementara.

\section{Kulaifikasi dan Kompetensi Pramuwisata}

Dari aspek kualifikasi pendidikan dan pengalaman mengikuti pelatihan menunjukkan varaibel yang cukup beragam. 
Tabel 5. Kualifikasi pemandu wisata kawasan Geopark Ciletuh Palabuhanratu

\begin{tabular}{lcr}
\hline Kualifikasi & F & \multicolumn{1}{c}{$\%$} \\
\hline Sekolah Dasar & 3 & 7,14 \\
SMP & 4 & 9,52 \\
SMA & 17 & 40,47 \\
Sarjana & 18 & 42,86 \\
Others & 0 & 0 \\
\hline & 42 & 100 \\
\hline
\end{tabular}

Sumber: Penelitian 2020

Jika melihat kualifikasinya, dinilai masih kurang memenuhi standar. Jika dibandingkan dengan ketentuan yang berlaku di Australia, yaitu standar pemandu wisata minimal memperoleh Certificate III Guiding yaitu mereka yang pernah menempuh pendidikan 1 tahun atau setara dengan D-1 (Diploma 1) tentang kepemanduan. Hal ini disepakati oleh beberapa organisasi, terutama Professional Tour Guide Association Australia (PTGAA) dan Guides of Australia (GOA). Kompetensi yang akan diperoleh melalui pendidikan, sebut saja di Charles Darwin University Australia memiliki matakuliah: Winery Guide, Tourist Guide, Local Tour Guide, cultural guide, heritage guide, historical guide, interpretive guide, museum guide, nature-based site guide, site guide, and walking guide.

Selain masih rendah, perhatian dari pihak stakeholder juga sangat rendah. Mereka seperti tidak ada yang memperhatikan. Untuk memastikan bahwa mereka masih relatif kurang banyak pengalaman dan pengetahuan tentang kondisi wilayah geopark, penelitian melakukan test tentang geodiversity, biodiversity, dan cultural diversity. Jumlah butir soal ada 45 yaitu 15 butir soal mengukur pengetahuan tentang wawasan tentang geodiversity; 15 butir soal mengukur wawasan tentang biodiversity; dan 15 butir soal mengukur wawasan tentang cultural diversity. Tes dilakukan melalui aplikasi Quizizz sehingga skor nilainya bersifat akmulatif. Namun reliabilitas dan validitasnya cukup baik.

Tabel 6. Frekwensi mengikuti pelatihan

\begin{tabular}{lcc}
\hline $\begin{array}{l}\text { Jumlah pelatihan yang } \\
\text { pernah diikuti }\end{array}$ & $\mathrm{F}$ & $\%$ \\
\hline$<3$ kali & 33 & 78,6 \\
$4-8$ kali & 5 & 11,9 \\
$9-12$ kali & 4 & 9,5 \\
$>12$ kali & 0 & 0 \\
\hline & 42 & 100 \\
\hline
\end{tabular}

Sumber: Penelitian 2020

Dengan gambaran hasil test, nampaknya masih perlu terus dibina dan diberdayakan agar mereka meningkat kompetensinya. Sebagaimana telah dijelaskan di atas, mereka adalah "duta" yang mewakili semua pihak yaitu pemerintah daerah, badan pengelola, dan masyarakat pelaku bisnis lainnya di kawasan geopark seperti manajemen hotel, restoran, jasa angkutan, homestay, supermarket, dan lain-lain. Baik buruknya citranya kawasan wisata sebagian ada di beban tanggung jawab mereka.

Analisis peneliti terkait dengan tantangan industri 4.0 nampaknya pramuwisata di kawasan geopark masih perlu banyak pelatihan dan juga pemberdayaan dari berbagai pihak terutama tentang penguasaan teknologi era pariwisata 4.0.

Tabel 7. Persentasi Pertanyaan yang dijawab benar.

\begin{tabular}{lrrrrrr}
\hline & \multicolumn{2}{c}{ Geodiversity } & \multicolumn{3}{c}{ Biodiversity } & \multicolumn{2}{c}{ Cultural Diversity } \\
\cline { 2 - 7 } & F & $\%$ & F & $\%$ & F & $\%$ \\
\cline { 2 - 7 } Dijawab Benar & 274 & 35,13 & 268 & 34,36 & 86 & 33,08 \\
Dijawab Salah & 201 & 25,77 & 204 & 26,15 & 77 & 29,62 \\
Tidak menjawab & 305 & 39,10 & 308 & 39,49 & 97 & 37,31 \\
\hline
\end{tabular}




\section{SIMPULAN}

Kesimpulan yang dapat ditarik dari hasil penelitian ini adalah bahwa pramuwisata di Kawasan Geopark Ciletuh dan Palabuhanratu, kualifikasinya masih belum memadai dan kompetensinya juga masih relatif terbatas baik dalam penguasaan materi tentang geodiversiti, biodivrsiti, maupun cultur diversiti. Dalam menghadapi era Tourm 4.0, pramuwisata masih perlu pembinaan melalui pelatihan-pelatihan yang terintegrasi sebagaimana yang dipersyaratkan dalam standar sertifikasi pemandu wisata.

\section{REKOMENDASI}

Rekomendasi ditujukan kepada:

1. Pemerintah daerah, khususnya dinas pariwisata baik nasional, provinsi, maupun kabupaten diharapkan menyediakan anggaran pelatihan bagi para pramuwisata yang tergabung keanggotannya dalam organisasi HPI Jawa barat atau Kabupaten Sukabumi.

2. Pelaku usaha yang terkait dengan jasa pariwisata seperti hotel, restoran, jasa angkutan, homestay, supermarket, bank, money changer, dan lain-lain disarankan menyisihkan dana Corporate Social Responsibility atau (CSR) untuk menyelenggaran pelatihan secara bergilian bagi paramuwisata lokal yang saling menguntungkan.

3. Perguruan tinggi dapat berperan serta untuk memberdayakan pramuwisata melalui pengabdian kepada mayarakat.

\section{UCAPAN TERIMA KASIH}

Diucapkan terima kasih kepada Rektor Universitas Pendidikan Indonesia (UPI), Ketua LPPM UPI yang telah membantu pendanaan penelitian. Kepada Ketua dan anggota HPI DPC Kabupaten Sukabumi yang telah memberikan informasinya.

\section{DAFTAR PUSTAKA}

Ap, J. \& Wong, K.F. 2001. Case Study on Tour Guiding: Professionalism, Issues and Problems. Tourism Management. 22(1): 551563.

Asy'arie, M. 2019. 13 Rekomendasi Unesco, untuk Pengembangan Geopark CiletuhPalabuhanratu. Artikel. Available from: https://mansurasyarie.wordpress.com/2019/ 03/14/13-rekomendasi-unesco-untukpengembangan-geopark-ciletuhpalabuhanratu/

Black, R, Weiler, B; 2005. Quality Assurance and Regulatory Mechanisms in the Tour Guiding Industry: A systematic review; Journal of Tourism Studies; Vol. 16 No. 1, 2005, pp. 2436

Çetinkaya and Öter. 2016. Role of tour guides on tourist satisfaction level in guided tours and impact on re-visiting Intention: a research in Istanbul. EJTHR 2016; 7(1):40-54

Cohen, E. 1985. The Tourist Guide: The Origins, Structure and Dynamics of a Role.Annals of Tourism Research. 2 (1): 5-29

Cohen, E.H., Maurice, I. \& Cohen, E. 2002. A New Paradigm in Guiding the Madrich as a Model. Annals of Tourism Research. 29(4): 919-932.

Dahles, H. 2002. The Politics of Tour Guiding: Image Management of Indonesia. Annals of Tourism Research. 29(3): 783-800.

Korže. 2019. From Industry 4.0 to Tourism 4.0. Innovative Issues and Approaches in Social Sciences, Vol. 12, No. 3

Nurdin, 2019. Tourism 4.0 (Pariwisata 4.0): Konsep \& Contoh Lengkap Menurut Para Ahli. Artikel. Avalaible from: https://pemasaranpariwisata.com/2019/12/0 7/tourism-40/\#: :text=Ilustrasi\%20Revolusi\%20Industr i\&text=Jadi\%20dalam $\% 20 \mathrm{hal} \% 20 \mathrm{ini} \% 20 \mathrm{ba}$ hwa,menjadi\%20lebih\%20cerdas\%20(smart ).

Yu, X., Weiler, B. \& Ham, S. 2001. Intercultural Communication and Meditation: A Framework for Analyzing the Intercultural Competence of Chinese Tour Guides. Journal of Vacation Marketing. 8(1):75-87. 